\title{
INTEGRATING GRADIENT SEARCH, LOGISTIC REGRESSION AND ARTIFICIAL NEURAL NETWORK FOR PROFIT BASED UNIT COMMITMENT
}

\author{
A.Amudha \\ Research Scholar, Department of EEE, Anna University, Tiruchirappalli- 620024 \\ +91-044-24502430, +91-044-24501270,E-mail: amudhaajay@ rediffmail.com \\ C.Christober Asir Rajan \\ Associate Professor, Department of EEE, Pondicherry Engineering College, Pondicherry - 605014 \\ +91-0413-2655281, +91-0413-2655101, E-mail: asir_70@pec.edu
}

Received 7 June 2012

Accepted 17 June 2013

\begin{abstract}
As the electrical industry restructures many of the traditional algorithms for controlling generating units, they need either modification or replacement. In the past, utilities had to produce power to satisfy their customers with the objective to minimize costs and actual demand/reserve were met. But it is not necessary in a restructured system. The main objective of restructured system is to maximize its own profit without the responsibility of satisfying the forecasted demand. The Profit Based Unit Commitment (PBUC) is a highly dimensional mixed-integer optimization problem, which might be very difficult to solve. Hence integrating Optimization Technique Gradient Search (GS), Logistic Regression (LR) and Artificial Neural Network (ANN) approach is introduced in this paper considering power and reserve generating in order to receive the maximum profit in three and ten unit system by considering the softer demand. Also this method gives an idea regarding how much power and reserve should be sold in markets. The proposed approach has been tested on a power system with 3 and 10 generating units. Simulation results of the proposed approach have been compared with the existing methods. It is observed that the proposed algorithm provides maximum profit compared to existing methods.
\end{abstract}

Keywords: Artificial neural network, Competitive environment, Deregulation, Gradient search, Logistic Regression, Profit Based Unit Commitment, Restructured system

\section{Introduction}

Power Industry is undergoing restructuring throughout the world. The past decade has seen a dramatic change in the manner in which the power industry is organized. It has moved from a formally vertically integrated and highly regulated industry to one that has been horizontally integrated in which generation, transmission and distribution are unbundled.
The basic aim of GENCOs (Generating Company) in restructuring of power system is to create competition among generating companies and provide choice of different generation options at a competitive price to consumers. The main objective of GENCOs is to maximize their own profit by considering the softer demand. In the past, utilities had to produce power to satisfy their customers with the minimum production 
cost. This means utilities run Unit Commitment (UC) with the condition that demand and reserve must be met.

In this paper, the authors intend to explain the importance of open market environment to GENCO that gives an idea for power producers to maximize their own profit as well as to maintain the power quality to consumers. Because of the fast economic development, the electricity demand is growing rapidly and the power system expansion becomes a severe economic burden of the government and a bottleneck of overall economy sustainable development.

It is urgent to launch power system restructuring and deregulation and to establish power markets with fair competition so as to attract more investments from various sources to power industry. In [2] it is impossible to predict the future UC scheduling, but with the Genetic Based Unit Commitment Algorithm (GBUCA) ability, good UC schedules and reasonable computer execution time using the true costing approach can be obtained The authors have reported research illustrating how power producers make decisions when having the option of selling to both the spot power market and reserve market [3]. GBUCA was updated for the PBUC-GA and to provide the user with additional information that identifies which schedules ,allow the user more market flexibility for given level of profit [4]. But disadvantages of the GA solution for PBUC problem are that the final solution being heuristic in nature may not be satisfactory. In [7] the author gives an overview of concept of UC problem with a bibliographical survey of relevant back ground, and provides a representative sample of current engineering thinking pertaining to the next generation UC problem. Hybrid method LR-EP has been used for solving the PBUC problem due to their ability to solve PBUC problems more efficiently [6], [15].

PBUC problems were solved by using conventional methods such as Dynamic Programming (DP) and Lagrange Relaxation (LR) methods [10] previously. Due to the curse of dimensionality with increase in number of generating units, LR method suffers from numerical convergence and DP method takes huge computational time to obtain an optimal solution. The Muller method was introduced to solve economic dispatch problem and Improved Pre- prepared Power Demand Table was introduced to solve combinatorial sub problem for deregulated environment without the effect of $r$ where $r$ is the probability that the reserve is called and generated [11].

The formulation in [12] maximizes the firm's profit based on the forecasted Locational Marginal Prices (LMPs). In paper [13], price uncertainty is modeled in a procedure using fuzzy members for maximizing a GENCO's profit. In paper [14], the formulation and solution of security constrained unit commitment solves simultaneous optimization of energy and ancillary services markets. In paper [16], a methodology is proposed for managing risks faced by power producers trading in energy market a day ahead. In paper [17] ,Quantum-Inspired Evolutionary Algorithm (QEA) is applied to solve the UC problem and proposes novel QEA-based UC method (QEA-UC) in which the unitscheduling problem is handled by QEA and the economic dispatch problem is solved by the commonlyused method, Lambda-Iteration Technique. The author in paper [18] investigates modeling approaches for the computational cost reduction of Stochastic UC formulations. Long term UCP was considered without ramp rate limit constraints of individual units [19]. In paper [20] ,Quantum Inspired Binary Particle Swarm Optimization (QBPSO) is based on the concept and principles of quantum computing and developed to enhance the conventional Binary Particle Swarm Optimization(BPSO)in solving the combinatorial optimization problems. In paper [21], Transmission switching (TS) was integrated with UC for solving the multi interval optimal generation unit scheduling with security constraints .Hybrid Particle Swarm Optimization (HPSO) which is a blend of BPSO and Real Coded particle Swarm Optimization (RCPSO)is proposed in [22]. The UC problem is handled by BPSO, while RCPSO solves the economic load dispatch problem. Both algorithms run simultaneously, adjusting their solutions in search of a better solution.

From the literature survey, it is observed that most of the existing algorithms have some limitations to provide the qualitative solution. The proposed method considers both power and reserve generation at the same time. This paper is organized as follows: Part II briefly describes the UC problem formulation and 
highlights modification needed for the competitive environment. Part III explains the market structure of selling power and energy. Part IV discusses the fundamentals of Gradient Search (GS), Logistic Regression (LR) and Artificial Neural Network (ANN) and its implication on PBUC. Finally, part $\mathrm{V}$ provides conclusion and future scope of the work.

\section{Problem Formulation}

The objective of UC is not to minimize costs as before but to provide the maximum profit for a company. It is an optimization problem and can be formulated mathematically by the following equations.

The Objective function is

$$
\operatorname{MaxP} . F=T C
$$

(or)

$$
\operatorname{Min} T C=R V
$$

Subject to

$$
\begin{gathered}
\sum_{i=1}^{N} P_{i t} X_{i t} \leq D_{t}^{\prime}, \quad t=1 \ldots \ldots \ldots . T \\
\sum_{i=1}^{N} R_{i t} X_{i t} \leq S R_{t}^{\prime}, \quad t=1 \ldots \ldots \ldots . T
\end{gathered}
$$

Redefining the UC problem for the competitive environment involves changing the demand and reserve constraints from an equality to less than or equal to the forecasted level if it creates more profit.

$$
\begin{aligned}
& P_{i \text { min }} \leq P_{i} \leq P_{i \max } \\
& 0 \leq R_{i} \leq P_{i \max }-P_{i \text { min }} \\
& R_{i}+P_{i} \leq P_{i \max }
\end{aligned}
$$

Minimum Up and Downtime constraints: where variables are defined as follows:

$P F \quad$ profit of Genco ;

$R V$ revenue of Genco;

$T C$ total cost of Genco;

$P_{i t} \quad$ power generation of generator at hour $\mathrm{t}$;
$R_{i t}$ reserve generation of generator at time t;

$X_{i t} \quad$ on/off status of generator at hour t;

$D^{\prime}{ }_{t}$ forecasted demand at hour t;

$S R_{t}^{\prime}$ forecasted reserve at hour $\mathrm{t}$;

$P_{i \text { min }}$ minimum generation limit of generator i ;

$P_{i \max }$ maximum generation limit of generator I;

$N \quad$ number of generator units;

$T$ number of hours;

Here forecasted demand, reserve and prices are important inputs to the PBUC algorithm; they are used to determine the expected revenue (1), which affects the expected profit.

\section{Power producer Strategies for selling power and}

\section{reserve}

If a power producer is able to sell power in to a reserve market, then the producer's strategies for profit maximization in both the spot and reserve markets are intertwined. The producer decides to pi (S) in the spot market and $\mathrm{Pi}(\mathrm{R})$ in the reserve market. The exact determination of $\mathrm{Pi}(\mathrm{S}) \& \mathrm{Pi}(\mathrm{R})$ depends on the way reserve payments are made, although results are very similar. (3)

\subsection{Payment for Power Delivered}

In this method, the reserve is paid when only it is actually used. Therefore, the reserve price is higher than the power (spot) price. Revenue and cost in (1) can be calculated from

$$
\begin{gathered}
R V=\sum_{i=1}^{N} \sum_{t=1}^{T}\left(P_{i t} \cdot S P_{t}\right) \cdot X_{i t}+\sum_{i=1}^{N} \sum_{t=1}^{T} r \cdot R P_{t} \cdot R_{i t} X_{i t} \\
T C=(1-r) \sum_{i=1}^{N} \sum_{t=1}^{T} F\left(P_{i t}\right) \cdot X_{i t}+r \sum_{i=1}^{N} \sum_{t=1}^{T} F\left(P_{i t}+R_{i t}\right) \cdot X_{i t}+S T \cdot X_{i t} \text { (9) }
\end{gathered}
$$

Where

$S P_{t}$-forecasted Spot price at hour $\mathrm{t}$

$R P_{t}$ - forecasted reserve price at hour $\mathrm{t}$

$F_{i}$-fuel cost function of generator i

$S T$ - start up cost.

$r$ - probability that the reserve is called and generated

\subsection{Payment for reserve allocated}

In this method, GENCO receives the reserve price per unit of reserve for every time period that the reserve is allocated and not used. When the reserve is used, 
GENCO receives the spot price for the reserve that is generated. In this method, reserve price is much lower than the spot price. Revenue and costs in (1) can be calculated from.

$R V=\sum_{i=1}^{N} \sum_{t=1}^{T}\left(P_{i t} \cdot S P_{t}\right) \cdot X_{i t}+\sum_{i=1}^{N} \sum_{t=1}^{T}\left((1-r) \cdot R P_{t}+r \cdot S P_{t}\right) R_{i t} X_{i t}$

$T C=(1-r) \sum_{i=1}^{N} \sum_{t=1}^{T} F\left(P_{i t}\right) \cdot X_{i t}+r \sum_{i=1}^{N} \sum_{t=1}^{T} F\left(P_{i t}+R_{i t}\right) \cdot X_{i t}+S T \cdot X_{i t}$

Where

$F\left(P_{i t}\right)$ is the Generator's fuel cost function and it can be expressed as $a_{i}+b_{i} p_{i t}+c_{i} p_{i t}{ }^{2}$ in which $a_{i}, b_{i}$ and $c_{i}$ are generator's constants.

\section{Proposed Methodology}

The proposed methodology deals with solving the UC problem in a fitting way than all the previous methods defined for the same cause. Gradient Descent (GD) proves to be the best possible machine learning optimization available to determine the global minima of a particular function. Similarly Logistic regression is the recent and most efficient technique in predicting the Best Fit among binary status options, generator on/off status in this case, using a predefined criterion or a training data set. The hybrid obtained between these techniques applies state of the act machine learning techniques to the unit commitment problem.

Gradient Descent (GD) is a met heuristic optimization algorithm used to obtain the global or near global minimum of most functions. Gradient descent is based on the observation that if the multivariable function is defined $\mathrm{F}(\mathrm{x})$ and differentiable in a neighborhood of a point a, then $F(x)$ decreases very fast if one goes from a in the direction of the negative gradient of $F$ at a.

For $\quad \alpha \geq 0$ a small enough number, then $F(a) \geq F(b)$. With this observation in mind, one starts with a guess $\mathbf{x}_{\mathbf{0}}$ for a local minimum of $F$, and considers the sequence $\mathrm{x}_{0}, \mathrm{x}_{1}, \mathrm{x}_{2} \ldots$ such that

$\mathrm{x}_{\mathrm{n}+1}=\mathrm{x}_{\mathrm{n}}-$

$\mathrm{n} \geq 0$ where $\alpha$ is the learning rate

We have

$$
F\left(X_{0}\right) \geq F\left(X_{1}\right) \geq F\left(X_{2}\right)
$$

so hopefully the sequence $\left(\mathrm{x}_{\mathrm{n}}\right)$ converges to the desired local minimum. Note that the value of the step size $\gamma$ is allowed to change in each iteration Here $F$ is assumed to be defined on the plane, and that its graph has a bowl shape. The blue curves are the contour lines, that is, the regions on which the value of $F$ is constant. A red arrow originating at a point shows the direction of the negative gradient at that point. Note that the (negative) gradient at a point is orthogonal to the contour line going through that point. We see that gradient descent leads us to the bottom of the bowl, that is, to the point where the value of the function $F$ is minimal.

Logistic regression (LR) is used for prediction of the probability of occurrence of an event by fitting data to a logistic function. It is a generalized linear model used for binomial regression. Like other forms of regression analysis, it makes use of one or more predictor variables that may be either numerical or categorical. The logistic function used in solving logistic regression

is, Where $f(Z)=\frac{1}{1+e^{-z}}$

$\mathrm{z}$ is the input to the sigmoid function, $z=\theta^{T} X$

$\mathrm{x}$ is the input to the logistic regression classifier.

$f(z)$ is the event probability.

The function is sometimes called sigmoid function and it takes the values between 0 and1. Therefore it predicts only the probability of the event happening. Thus it is a suitable tool for solving the onloff criterion based on the constraints.

An artificial neural network (ANN), usually called neural network $(\mathrm{NN})$, is a mathematical model or computational model that is inspired by the structure and/or functional aspects of biological neural networks. A neural network consists of an interconnected group of artificial neurons, and it processes information using a connectionist approach to computation. In most cases an ANN is an adaptive system that changes its structure based on external or internal information that flows through the network during the learning phase. Modern neural networks are non-linear statistical data modeling tools. They are usually used to model complex relationships between inputs and outputs or to find patterns in data. 


\subsection{Network function}

The word network in the term 'artificial neural network' refers to the inter-connections between the neurons in the different layers of each system. An example system has three layers. The first layer has input neurons, which send data via synapses to the second layer of neurons, and then via more synapses to the third layer of output neurons. More complex systems will have more layers of neurons with some having increased layers of input neurons and output neurons. The synapses store parameters called "weights" that manipulate the data in the calculations.

An ANN is typically defined by three types of parameters:

1. The interconnection pattern between different layers of neurons

2. The learning process for updating the weights of the interconnections

3. The activation function that converts a neuron's weighted input to its output activation.

Mathematically, a neuron's network function $f(x)$ is defined as a composition of other functions $g_{i}(x)$, which can further be defined as a composition of other functions. This can be conveniently represented as a network structure, with arrows depicting the dependencies between variables. A widely used type of composition is the nonlinear weighted sum, where $f(x)=k\left(\sum_{i} w_{i} g_{i}(x)\right)$, where $\mathrm{k}$ is commonly referred to as the activation function is some predefined function, such as the hyperbolic tangent. It will be convenient for the following to refer to a collection of functions $\mathrm{g}_{\mathrm{i}}$ as simply a vector $\mathrm{g}\left(\mathrm{g}_{1}, \mathrm{~g}_{2}, \ldots, \mathrm{g}_{\mathrm{n}}\right)$.

The first view is the functional view: the input xis transformed into a 3 -dimensional vector $h$, which is then transformed into a 2-dimensional vector $\mathrm{g}$, which is finally transformed into $\mathrm{f}$. This view is most commonly encountered in the context of optimization. The second view is the probabilistic view: the random variable $F=f(G)$ depends upon the random variable, $G$ $=\mathrm{g}(\mathrm{H})$ which depends upon $\mathrm{H}=\mathrm{h}(\mathrm{X})$, which depends upon the random variable $\boldsymbol{X}$. This view is most commonly encountered in the context of graphical models.
The two views are largely equivalent. In either case, for this particular network architecture, the components of individual layers are independent of each other (e.g., the components of $\mathrm{g}$ are independent of each other given their input $\mathrm{h}$ ). This naturally enables a degree of parallelism in the implementation.

Networks such as the previous one are commonly called feed forward, because their graph is a directed acyclic graph. Networks with cycles are commonly called recurrent. Such networks are commonly depicted in the manner shown at the top of the figure, where $f$ is shown as being dependent upon itself. However, an implied temporal dependence is not shown.

\subsection{Learning}

What has attracted the most interest in neural networks is the possibility of learning. Given a specific task to solve, and a class of functions $\mathrm{F}$, learning means using a set of observations to find $f^{*} \in F$ which solves the task in some optimal sense.

This entails defining a cost function $\mathrm{C}: \mathrm{F} \rightarrow \mathrm{R}$ such that, for the optimal solution $f^{*} c\left(f^{*}\right) \leq c(f) \forall f \in F$ (i.e., no solution has a cost less than the cost of the optimal solution).

The cost function $\mathrm{C}$ is an important concept in learning, as it is a measure of how far away a particular solution is from an optimal solution to the problem to be solved. Learning algorithms search through the solution space to find a function that has the smallest possible cost.

For applications where the solution is dependent on some data, the cost must necessarily be a function of the observations; otherwise we would not be modeling anything related to the data. It is frequently defined as a statistic to which only approximations can be made. As a simple example, consider the problem of finding the model f, which minimizes $C=E\left[(f(x)-y)^{2}\right]$, for data pairs(x, y) drawn from some distribution D. In practical situations we would only have $\mathrm{N}$ samples from $\mathrm{D}$ and thus, for the above example, we would only minimize

$\hat{C}=\frac{1}{N} \sum_{i=1}^{N}\left(f\left(x_{i}\right)-y_{i}\right)^{2}$.

Thus, the cost is minimized over a sample of the data rather than the entire data set.

When $N \rightarrow \infty$ some form of online machine learning must be used, where the cost is partially minimized as 
each new example is seen. While online machine learning is often used when $\mathcal{D}$ is fixed, it is most useful in the case where the distribution changes slowly over time. In neural network methods, some form of online machine learning is frequently used for finite datasets.

\subsection{Hybrid between GD-LR using ANN}

This method first involves the determination of minimum fuel cost of each generator from the function defined (1) using gradient descent. Next the power corresponding to the minimum fuel cost is determined.

$$
\begin{array}{ll}
\text { If } \mathrm{P}_{\text {mincost }}<\mathrm{P}_{\text {min }} & \mathrm{P}_{\text {mincost }}=\mathrm{P}_{\text {min }} \\
\text { If } \mathrm{P}_{\text {mincost }}>\mathrm{P}_{\max } & \mathrm{P}_{\text {mincost }}=\mathrm{P}_{\text {max }}
\end{array}
$$

Then the dataset consisting of all the power values at an increment of one unit from $\mathrm{P}_{\text {mincost }}$ to $\mathrm{D}_{\mathrm{t}}$ ' is formed.

This dataset is fed to the logistic regression classifier. The logistic regression is already trained with a classifier dataset obtained by applying the required constraints to the available dataset. Thus the classifier is trained to a parameter set $\boldsymbol{\theta}$ which is obtained by minimizing the cost function,

$$
J(\theta)=\frac{1}{m} \sum_{i=1}^{m}\left[-Y^{(i)} \log \left(h_{e}\left(X^{(i)}\right)-\left(1-y^{(i)}\right) \log \left(1-h_{e}\left(x^{(i)}\right)\right]\right.\right.
$$

Where

$y^{(i)} \quad$ status of generator $i$ corresponding to the $\mathrm{P}_{\text {mincost }}$

$\mathrm{h}_{\theta}\left(\mathrm{x}^{\mathrm{i})}\right)$ Predicted status of generator $\mathrm{i}$ for supplying the entire forecasted demand.(subject to sigmoid function in equation 3 )

$\mathrm{m}$ product of total number of generators and number of hours

$\mathrm{J}(\theta) \quad$ cost function

This parameter set theta is multiplied to the input forecasted power and the status of the generator corresponding to the hour of demand is found by feeding it to the sigmoid function as described by (12). This output of the sigmoid function is deciphered as,

$X_{\text {it }}=1$ if $f\left(z_{i t}\right) \geq 0.5$

$X_{\text {it }}=0$ if $f\left(z_{i t}\right)<0.5$

Where

$\mathrm{X}_{\mathrm{it}}$ is the on/off status of generator described in Equations (8) and (9). $\mathrm{f}\left(\mathrm{z}_{\mathrm{it}}\right)$ is the predicted probability of the generator being turned ON which is the output of logistic regression classifier.

The value of 0.5 is decided assuming zero bias conditions of generators. But they can be redefined to various values depending on the precision and recall values.

This on/off status uses an artificial neural network to decide the power limit between switching on a new generator. This dynamic power varies as a function of the forecasted demand. This demand if exceeds the particular limit as set by the ANN, the next generator status is turned to ON. It uses a single direction logic, multi- input forward backward prediction algorithm. The network has 6 inputs and a hidden layer of 6 units and one output unit which gives a dynamic value of the power difference for each stage. The ANN is implemented just once to make sure that computational overhead is avoided. The stage uses forecasted demand to predict the power difference for each stage which is fed to the logistic regression classifier for the prediction process. This constraint is a main factor in deciding the On/Off status for the machine as this value is given a very high weightage is given to this parameter during mean normalization. The cost function and network parameters are as defined earlier.

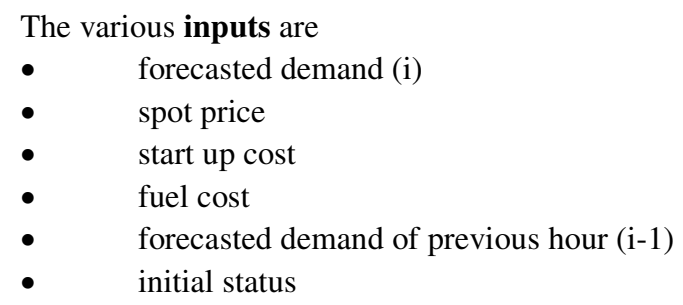

The output is the power difference for the current hour (i) which opens up the next generator. This neural function aids the improvement of the reliability of the system and thus improving the efficiency to a considerably higher level than using a static prediction of data from forecasted demand. This On/off status along with the power dataset is fed to the total cost function where the profit of each of the possible combination of power is calculated. The entire value is negated and the global minimum of the function is determined using the gradient descent operation (which is called gradient ascent). Thus the maximum value of 
the profit obtained and the corresponding power are calculated by the algorithm.

The dataset used to train logistic regression is regenerated by the principle of symmetry subject to the constraints. The main constraint that is maintained to improve the profit is

$\mathrm{T}_{\text {on }} \geq$ minimum up time

$\mathrm{T}_{\text {off }} \geq$ minimum down time

This regeneration creates a huge dataset thus enabling the better performance of the classifier. The generator has to be scheduled to generate its rated power at the hour it is marked on. Thus the up time is considered for the process also. After the process is complete the generated power and the on/off status is supplied to the same logistic regression classifier to check the reserve generation of limit of each generator and the iteration process is repeated for reserve to find the reserve generation ranging from 0 to $\mathrm{SR}_{\mathrm{t}}$ '. The final profit of the GENCO is calculated. The learning rate of the classifier for the reserve power is maintained at a relatively less value to enable proper convergence of metaheuristic minimization technique.

\section{ALGORITHM}

1 Start the process

2 Obtain the input data (number of generators, demand hours, forecasted demand and forecasted price)

3 Check if the current time period exceeds the required demand period

4 Find power corresponding to minimum cost of each generator, by feeding the cost curve and a suitable learning rate to the gradient descent algorithm

$5 \mathrm{By}$ iterating from the value obtained in step 4 to the maximum limit, find all the possible values of profit in steps of one (assuming each generator is on)

6 Find the maximum profit and the power corresponding to it, by feeding the data input and the learning rate to the gradient descent algorithm

7 The minimum difference in power between the demands for the generators to turn on is fixed dynamically for each generator by the ANN classifier which takes demand, fuel cost, profit and the demand sustenance (how much time the demand stays) given by Ton $>>$ Tstart, as input parameters
8 Feed the input data such as number of generators, demand, maximum and minimum limit, constraints, power difference from step 7 and others to the logistic regression classifier

9 Multiply the output schedule of generators (binary value $(0,1))$ with the power obtained in step 6 and sum them up to obtain the total power supplied

10 Find the corresponding cost, revenue and profit

11 Separate the reserve power if it gives better profit by iterating over the profit values for various combinations 12 Stop when the process is complete for all the demand hours

\section{Numerical Results}

The proposed method has been implemented in Matlab and tested using two different systems to solve PBUC problem. Before running PBUC-GS, LR and ANN, the Gencos need to get an accurate hourly demand and price forecast for the scheduling period. Fuel cost function of each generator is estimated into quadratic form. Based on the forecasted information, power is dispatched economically by the proposed method. Simulations are carried out to find optimal solution, and profit and they are also compared with existing methods. The proposed method considers the effect of probability that reserve is called and generated for 3 and 10 unit system. The forecasted demand, forecasted prices and fuel cost data of 3 unit system are listed in TableA1 and TableA2. In PBUC, Gencos no longer have the obligation to meet the demand. Gencos may choose to generate less than the demand.

\section{Three Unit Systems}

The effect of probability that reserve is called and generated (r) is tested using 3 generator 12 hour test data. Here, reserve price is fixed at the triple and 0.01 times of spot price for reserve payment method $\mathrm{A}$ and $\mathrm{B}$, respectively, while is $\mathrm{r}$ varied from 0.005 to 0.05 . Simulation results are shown in Tables I and II, and it is clear that profit obtained by method $\mathrm{A}$ is higher than method B when $r$ is varied. In method A, reserve is paid only when the reserve power is actually delivered and used. Profit is more sensitive when $r$ is varied.

The effect of reserve price is investigated in reserve payment method A and method B. In this case $r$ is fixed at 0.005 while the reserve price is varied. From table III and table IV, it is observed that profit obtained by 
Table I

Effect of ' $r$ ' in reserve payment Method A (reserve price = $3 *$ spot price)

\begin{tabular}{|c|c|c|}
\hline $\mathbf{r}$ & $\begin{array}{c}\text { Profit(\$) } \\
\text { (LR-EP) }\end{array}$ & $\begin{array}{c}\text { Profit(\$) } \\
\text { (proposed) }\end{array}$ \\
\hline 0.005 & 9074.35 & 10228 \\
\hline 0.010 & 9094.23 & 10234 \\
\hline 0.015 & 9116.18 & 10241 \\
\hline 0.020 & 9140.40 & 10247 \\
\hline 0.025 & 9166.98 & 10254 \\
\hline 0.030 & 9195.88 & 10260 \\
\hline 0.035 & 9228.00 & 10267 \\
\hline 0.040 & 9262.87 & 10273 \\
\hline 0.045 & 9300.76 & 10280 \\
\hline 0.050 & 9340.77 & 10287 \\
\hline
\end{tabular}

Table II

Effect Of ' $r$ ' in Reserve Payment Method B (reserve price = $.01 *$ spot price)

\begin{tabular}{|c|c|c|}
\hline $\mathbf{r}$ & $\begin{array}{c}\text { Profit(\$) } \\
\text { (LR-EP) }\end{array}$ & $\begin{array}{c}\text { Profit(\$) } \\
\text { (proposed) }\end{array}$ \\
\hline 0.005 & 9074.26 & 10227 \\
\hline 0.010 & 9075.40 & 10228.2 \\
\hline 0.015 & 9076.53 & 10228.6 \\
\hline 0.020 & 9077.67 & 10229.1 \\
\hline 0.025 & 9078.80 & 10229.7 \\
\hline 0.030 & 9079.93 & 10230.3 \\
\hline 0.035 & 9081.07 & 10230.8 \\
\hline 0.040 & 9082.20 & 10231.2 \\
\hline 0.045 & 9083.34 & 10231.7 \\
\hline 0.050 & 9084.47 & 10232 \\
\hline
\end{tabular}

method B is higher than method A. For method B, reserve is paid all the time even reserve is not delivered. Here profit is more sensitive when reserve price is varied. Here profit is more sensitive when reserve price is varied.

Table III

Effect of Reserve Price in Payment Method A (r=0.005)

\begin{tabular}{|c|c|c|}
\hline $\begin{array}{l}\text { Reserve } \\
\text { price } \\
\text { (times } \\
\text { of spot } \\
\text { price) }\end{array}$ & $\begin{array}{l}\text { Profit(\$) } \\
\text { LR-EP } \\
\text { Method }\end{array}$ & $\begin{array}{l}\text { Profit }(\$) \\
\text { Proposed } \\
\text { Method }\end{array}$ \\
\hline 1 & 9057.72 & 10221 \\
\hline 2 & 9065.78 & 10224 \\
\hline 3 & 9074.35 & 10228 \\
\hline 4 & 9083.42 & 10231 \\
\hline 5 & 9093.00 & 10234 \\
\hline 6 & 9103.07 & 10237 \\
\hline 7 & 9113.65 & 10240 \\
\hline 8 & 9124.75 & 10243 \\
\hline 9 & 9136.48 & 10246 \\
\hline 10 & 9148.75 & 10249 \\
\hline & \multicolumn{2}{|c}{} \\
\hline
\end{tabular}

Table IV

Effect Of Reserve Price In Reserve Payment Method B $(\mathrm{r}=.005)$

\begin{tabular}{|c|c|c|}
\hline $\begin{array}{c}\text { Reserve } \\
\text { price } \\
\text { (times } \\
\text { of spot } \\
\text { price) }\end{array}$ & $\begin{array}{c}\text { Profit(\$) } \\
\text { ( LR-EP }\end{array}$ & $\begin{array}{c}\text { Profit(\$) } \\
\text { (proposed) }\end{array}$ \\
\hline 0.01 & 9074.26 & 10227 \\
\hline 0.02 & 9092.80 & 10223 \\
\hline 0.03 & 9113.33 & 10239 \\
\hline 0.04 & 9136.00 & 10245 \\
\hline 0.05 & 9160.90 & 10251 \\
\hline 0.06 & 9187.94 & 10257 \\
\hline 0.07 & 9217.76 & 10263 \\
\hline 0.08 & 9250.13 & 10269 \\
\hline 0.09 & 9285.20 & 10275 \\
\hline 0.10 & 9322.59 & 10281 \\
\hline
\end{tabular}

Table $\mathrm{V}$ and VI show examples of power and reserve scheduling plans for reserve payment methods A and B respectively. The results are compared with those obtained via the traditional UC algorithm and via the hybrid LR -EP profit-based unit commitment algorithm developed in [6],Muller method [11], LRACSA method[24] and profit is found to be higher as it is shown in Table VI1 for method A. In Table VIII, for method $\mathrm{B}$, results will be compared with those obtained via the traditional UC algorithm and hybrid BUC algorithm developed in [6] and profit is found to be higher.

Effect of probability of reserve is applied to both methods and it is observed that profit of method $\mathrm{A}$ is comparatively higher as shown in Fig 2. In Fig. 3 and Fig. 4 profit obtained by the proposed method is compared with LR- EP method for the method A and B respectively. From this it is observed that profit is high in 6 th and $7^{\text {th }}$ hour of time period.

\section{Ten unit systems}

In addition to three unit system, proposed algorithm worked well for larger system also. The forecasted demand and forecasted prices are listed in Table 6.The fuel cost data of 10 unit system are listed in Table 5 . Based on the forecasted information, power is dispatched economically with the effect of probability of reserve that is called and generated by the proposed method and it is shown in Table IX and Table $\mathrm{X}$ for reserve payment method A and B respectively. From 
Table V

Power and reserve generation of reserve payment method $\mathrm{A}(\mathrm{r}=.005$, reserve price $=3 *$ spot price $)$

\begin{tabular}{|c|c|c|c|c|c|c|c|c|c|c|c|c|c|c|}
\hline \multirow{3}{*}{ Hour } & \multicolumn{6}{|c|}{ PBUC by LR -EP[6] } & \multirow{3}{*}{ Profit (\$) } & \multicolumn{6}{|c|}{ PBUC by GS,LR \&ANN } & \multirow{3}{*}{ Profit $(\$$} \\
\hline & \multicolumn{3}{|c|}{ Power (MW) } & \multicolumn{3}{|c|}{ Reserve (MW) } & & \multicolumn{3}{|c|}{ Power (MW) } & \multicolumn{3}{|c|}{ Reserve (MW) } & \\
\hline & U1 & U2 & U3 & U1 & U2 & U3 & & U1 & $\mathbf{U} 2$ & U3 & U1 & $\mathbf{U} 2$ & U3 & \\
\hline 1 & $\mathbf{0}$ & $\mathbf{0}$ & 170 & $\mathbf{0}$ & $\mathbf{0}$ & 20 & 531.4 & $\mathbf{0}$ & 0 & 169.6 & $\mathbf{0}$ & 0 & 20 & 529.47 \\
\hline 2 & 0 & 0 & 200 & 0 & 0 & 0 & 570 & 0 & 0 & 199.6 & 0 & 0 & 0 & 568.7 \\
\hline 3 & 0 & 0 & 200 & 0 & 0 & 0 & 300 & 0 & 0 & 199.6 & 0 & 0 & 0 & 300.62 \\
\hline 4 & 0 & 0 & 200 & 0 & 0 & 0 & 390 & 0 & 0 & 199.6 & 0 & 0 & 0 & 390 \\
\hline 5 & 0 & 379.9 & 200 & 0 & 20.1 & 0 & 201 & 0 & 399 & 200 & 0 & 0 & 0 & 501.25 \\
\hline 6 & 0 & 400 & 200 & 0 & 0 & 0 & 1350 & 400 & 400 & 200 & 0 & 0 & 0 & 1829.01 \\
\hline 7 & 0 & 400 & 200 & 0 & 0 & 0 & 1380 & 400 & 400 & 200 & 0 & 0 & 0 & 1878.97 \\
\hline 8 & 0 & 400 & 200 & 0 & 0 & 0 & 990 & 0 & 399 & 200 & 0 & 0 & 0 & 1290.39 \\
\hline 9 & 0 & 400 & 200 & 0 & 0 & 0 & 810 & 0 & 399 & 200 & 0 & 0 & 0 & 1110.79 \\
\hline 10 & 0 & 130 & 200 & 0 & 35 & 0 & 818.1 & 0 & 329 & 0 & 0 & 35 & 0 & 686.89 \\
\hline 11 & 0 & 200 & 200 & 0 & 40 & 0 & 804.6 & 0 & 399 & 0 & 0 & 0 & 0 & 600.52 \\
\hline \multirow[t]{2}{*}{12} & 0 & 350 & 200 & 0 & 50 & 0 & 829.2 & 0 & 399 & 0 & 0 & 0 & 0 & 540.82 \\
\hline & & & & & & & 9074.3 & & & & & \multicolumn{2}{|c|}{ TOTAL } & 10,228 \\
\hline
\end{tabular}

Table VI

Power and reserve generation of reserve payment method $\mathrm{B}(\mathrm{r}=.005$, reserve price $=.04 \mathrm{x}$ spot price $)$

\begin{tabular}{|c|c|c|c|c|c|c|c|c|c|c|c|c|c|c|}
\hline \multirow{3}{*}{ Hour } & \multicolumn{6}{|c|}{ PBUC by LR -EP[6] } & \multirow{3}{*}{ Profit (\$) } & \multicolumn{6}{|c|}{ PBUC by GS ,LR\&ANN } & \multirow{3}{*}{ Profit (\$) } \\
\hline & \multicolumn{3}{|c|}{ Power (MW) } & \multicolumn{3}{|c|}{ Reserve (MW) } & & \multicolumn{3}{|c|}{ Power (MW) } & \multicolumn{3}{|c|}{ Reserve (MW) } & \\
\hline & U1 & U2 & U3 & U1 & U2 & U3 & & U1 & U2 & U3 & $\mathrm{U} 1$ & U2 & U3 & \\
\hline 1 & $\mathbf{0}$ & $\mathbf{0}$ & 170 & $\mathbf{0}$ & $\mathbf{0}$ & 20 & 537.7 & $\mathbf{0}$ & 0 & 169.6 & $\mathbf{0}$ & 0 & 20 & 535.76 \\
\hline 2 & 0 & 0 & 200 & 0 & 0 & 0 & 570 & 0 & 0 & 199.6 & 0 & 0 & 0 & 568.77 \\
\hline 3 & 0 & 0 & 200 & 0 & 0 & 0 & 300 & 0 & 0 & 199.6 & 0 & 0 & 0 & 300.62 \\
\hline 4 & 0 & 0 & 200 & 0 & 0 & 0 & 390 & 0 & 0 & 199.6 & 0 & 0 & 0 & 390 \\
\hline 5 & 0 & 330 & 200 & 0 & 70 & 0 & 215.7 & 0 & 399 & 200 & 0 & 0 & 0 & 501 \\
\hline 6 & 0 & 400 & 200 & 0 & 0 & 0 & 1350 & 400 & 400 & 200 & 0 & 0 & 0 & 1829 \\
\hline 7 & 0 & 400 & 200 & 0 & 0 & 0 & 1380 & 400 & 400 & 200 & 0 & 0 & 0 & 1878.97 \\
\hline 8 & 0 & 400 & 200 & 0 & 0 & 0 & 990 & 0 & 399 & 200 & 0 & 0 & 0 & 1290.39 \\
\hline 9 & 0 & 387.2 & 200 & 0 & 12.8 & 0 & 810.4 & 0 & 399 & 200 & 0 & 0 & 0 & 1110.79 \\
\hline 10 & 0 & 130 & 200 & 0 & 35 & 0 & 829.8 & 0 & 329 & 0 & 0 & 35 & 0 & 698.57 \\
\hline 11 & 0 & 200 & 200 & 0 & 40 & 0 & 817.4 & 0 & 399 & 0 & 0 & 0 & 0 & 600.52 \\
\hline \multirow[t]{2}{*}{12} & 0 & 350 & 200 & 0 & 50 & 0 & 945.0 & 0 & 399 & 0 & 0 & 0 & 0 & 540.82 \\
\hline & & & & & & & 9136 & & & & & \multicolumn{2}{|c|}{ TOTAL } & 10245 \\
\hline
\end{tabular}

Table VII

Comparison of the results of 3 unit system with existing methods by proposed method (Method -A)
Comparison of the results of 3 unit system with existing methods by proposed method (Method -B)

\begin{tabular}{|c|c|c|}
\hline S.no & Method & Profit (\$) \\
\hline 1 & Traditional UC[6] & 4048.8 \\
\hline 2 & PBUC by LR-EP method [6] & 9074.3 \\
\hline 3 & PBUC by Muller method [11] & 9030.5 \\
\hline 4 & PBUC by LR-ACSA method [24] & 9081.1 \\
\hline 5 & Proposed method & $\mathbf{0 2 2 8}$ \\
\hline
\end{tabular}

\begin{tabular}{|c|c|c|}
\hline S.no & Method & Profit (\$) \\
\hline 1 & Traditional UC[6] & 4262.7 \\
\hline 2 & PBUC by LR-EP method [6] & 9136.0 \\
\hline 5 & Proposed method & $\mathbf{1 0 2 4 5}$ \\
\hline
\end{tabular}




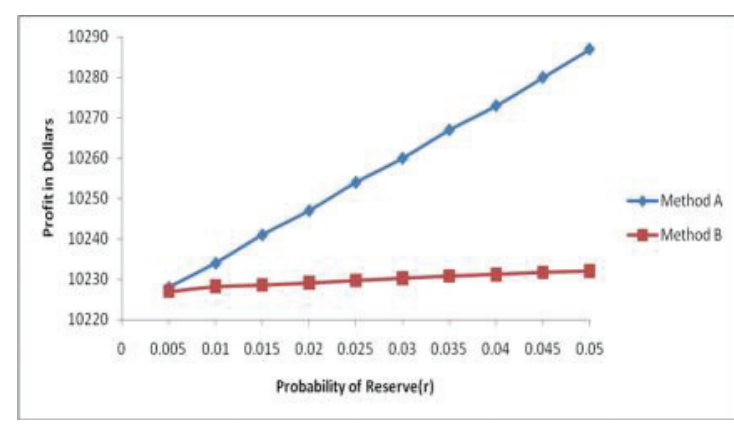

Fig 2. Effect of Probability of Reserve

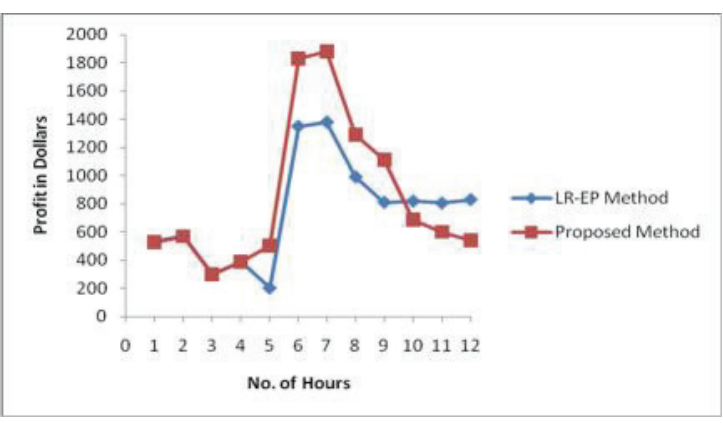

Fig 3. Comparison of Profit between LR-EP \& Proposed Method A

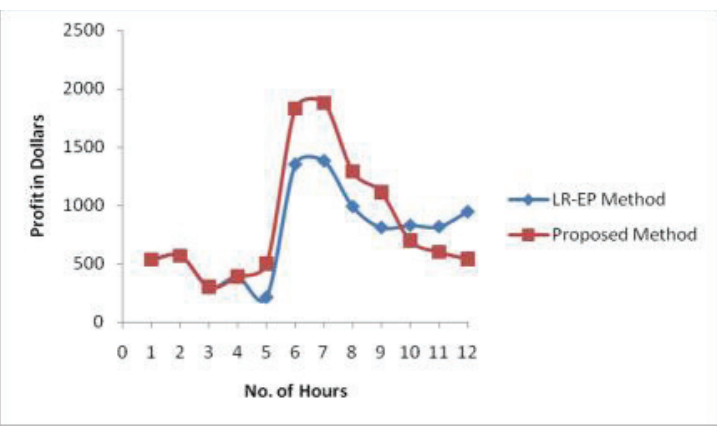

Fig 4. Comparison of Profit between LR-EP \& Proposed Method B

Table XI, it is clear that the proposed method provides maximum profit for method A compared to the existing methods of PBUC by LR-EP method [6 ], Muller method [11], MAS [23 ], TS -RP [26], TS - IRP [ 26] and improved PSO [25]. For method B ,profit obtained by LR-EP method [6 ] is compared with proposed method as shown in Table XII.

\section{Conclusion}

In this paper, the authors have proposed an algorithm to solve the PBUC for three and ten unit restructured power system. Based on forecasted demand, PBUC is solved with the effect of $r$. The effect of probability of reserve and reserve power is considered for three unit system and two types of reserve payment methods are simulated. All simulated results of three and ten unit system are compared with results of existing methods and it is observed that profit is obtained by the proposed method is higher. For further research, PBUC with transmission losses and emission constraints will be considered. With these constraints added, the end user can enjoy emission free economic power

Table XI

Comparison of the results of 10unit system $(24 \mathrm{Hr})$ with existing methods by proposed methodA

\begin{tabular}{|c|l|c|}
\hline S.no & \multicolumn{1}{|c|}{ Method } & Profit (\$) \\
\hline 1 & PBUC by LR-EP method [6] & 112818.93 \\
\hline 2 & PBUC by Muller method [11] & 103296 \\
\hline 3 & PBUC -MAS [23 ] & 109485.19 \\
\hline 4 & PBUC by TS -RP [26] & 101086. \\
\hline 5 & PBUC by TS - IRP [ 26] & 103261 \\
\hline 6 & PBUC by improved PSO [25] & 113018.7 \\
\hline 7 & Proposed method & $\mathbf{1 3 0 9 9 0}$ \\
\hline
\end{tabular}

Table XII

Comparison of the results of 10unit system $(24 \mathrm{Hr})$ with existing methods by proposed method B

\begin{tabular}{|c|l|l|}
\hline S.no & \multicolumn{1}{|c|}{ Method } & \multicolumn{1}{|c|}{ Profit (\$) } \\
\hline 2 & PBUC by LR-EP method [6] & 107838.58 \\
\hline 5 & Proposed method & $\mathbf{1 3 0 3 4 9}$ \\
\hline
\end{tabular}

TableA1 Forecasted Demand and Price for 3 Generator Case

\begin{tabular}{llll}
\hline Hour & $\begin{array}{l}\text { Forecasted } \\
\text { demand } \\
(\mathrm{MW})\end{array}$ & $\begin{array}{l}\text { Forecasted spot } \\
\text { price }(\$ / \mathrm{MW})\end{array}$ & $\begin{array}{l}\text { Forecasted } \\
\text { reserve(MW) }\end{array}$ \\
\hline 1 & 170 & 10.55 & 20 \\
2 & 250 & 10.35 & 25 \\
3 & 400 & 9.00 & 40 \\
4 & 520 & 9.45 & 55 \\
5 & 700 & 10.00 & 70 \\
6 & 1050 & 11.25 & 95 \\
7 & 1100 & 11.30 & 100 \\
8 & 800 & 10.65 & 80 \\
9 & 650 & 10.35 & 65 \\
10 & 330 & $11 ., 20$ & 35 \\
11 & 400 & 10.75 & 40 \\
12 & 550 & 10.60 & 55 \\
\hline
\end{tabular}


Table A2

Fuel cost data of 3 Generator Case

\begin{tabular}{lccc} 
& Unit 1 & Unit 2 & Unit 3 \\
\hline P max (Mw) & 600 & 400 & 200 \\
P min $(\mathrm{Mw})$ & 100 & 100 & 50 \\
$\mathrm{a}(\$ / \mathrm{h})$ & 500 & 300 & 100 \\
$\mathrm{~b}(\$ / \mathrm{Mwh})$ & 10 & 8 & 6 \\
$\mathrm{c}\left(\$ / \mathrm{Mw}{ }^{2} \mathrm{~h}\right)$ & 0.002 & 0.0025 & 0.005 \\
$\begin{array}{l}\text { Min up time } \\
\text { (h) }\end{array}$ & 3 & 3 & 3 \\
$\begin{array}{l}\text { Min down } \\
\text { time(h) }\end{array}$ & 3 & 3 & 3 \\
\hline $\begin{array}{l}\text { Startup cost } \\
(\$)\end{array}$ & 450 & 400 & 300 \\
\hline
\end{tabular}

Table A3

Forecasted Demand, Reserve and Spot Prices for Ten-Unit 24-Period System

\begin{tabular}{|c|c|c|c|}
\hline Hour & $\begin{array}{l}\text { Forecasted } \\
\text { Demand } \\
(\mathrm{MW})\end{array}$ & $\begin{array}{c}\text { Forecasted } \\
\text { Reserve } \\
(\mathrm{MW})\end{array}$ & $\begin{array}{c}\text { Forecasted } \\
\text { Spot Price }(\$ / \\
\text { MW-Hr) }\end{array}$ \\
\hline 1 & 700 & 70 & 22.15 \\
\hline 2 & 750 & 75 & 22.00 \\
\hline 3 & 850 & 85 & 23.10 \\
\hline 4 & 950 & 95 & 22.65 \\
\hline 5 & 1000 & 100 & 23.25 \\
\hline 6 & 1100 & 110 & 22.95 \\
\hline 7 & 1150 & 115 & 22.50 \\
\hline 8 & 1200 & 120 & 22.15 \\
\hline 9 & 1300 & 130 & 22.80 \\
\hline 10 & 1400 & 140 & 29.35 \\
\hline 11 & 1450 & 145 & 30.15 \\
\hline 12 & 1500 & 150 & 31.65 \\
\hline 13 & 1400 & 140 & 24.60 \\
\hline 14 & 1300 & 130 & 24.50 \\
\hline 15 & 1200 & 120 & 22.50 \\
\hline 16 & 1050 & 105 & 22.30 \\
\hline 17 & 1000 & 100 & 22.25 \\
\hline 18 & 1100 & 110 & 22.05 \\
\hline 19 & 1200 & 120 & 22.20 \\
\hline 20 & 1400 & 140 & 22.65 \\
\hline 21 & 1300 & 130 & 23.10 \\
\hline 22 & 1100 & 110 & 22.95 \\
\hline 23 & 900 & 90 & 22.75 \\
\hline 24 & 800 & 80 & 22.55 \\
\hline
\end{tabular}

TABLE A4 Unit Data (Ten-unit 24-Period System)

\begin{tabular}{|c|c|c|c|c|c|c|c|c|c|c|}
\hline & Unit 1 & Unit 2 & Unit 3 & Unit 4 & Unit 5 & Unit 6 & Unit 7 & Unit 8 & Unit 9 & Unit 10 \\
\hline Pmax & 455 & 455 & 130 & 130 & 162 & 80 & 85 & 55 & 55 & 55 \\
\hline Pmin & 150 & 150 & 20 & 20 & 25 & 20 & 25 & 10 & 10 & 10 \\
\hline $\mathbf{a}$ & 0.00048 & 0.00031 & 0.00200 & 0.00211 & 0.00398 & 0.00712 & 0.00079 & 0.00413 & 0.00222 & 0.00173 \\
\hline $\mathbf{b}$ & 16.19 & 17.26 & 16.60 & 16.50 & 19.70 & 22.26 & 27.74 & 25.92 & 27.27 & 27.79 \\
\hline c & 1000 & 970 & 700 & 680 & 450 & 370 & 480 & 660 & 665 & 670 \\
\hline min up & 8 & 8 & 5 & 5 & 6 & 3 & 3 & 1 & 1 & 1 \\
\hline min down & 8 & 8 & 5 & 5 & 6 & 3 & 3 & 1 & 1 & 1 \\
\hline ST & 4500 & 4500 & 550 & 560 & 900 & 170 & 260 & 30 & 30 & 30 \\
\hline Ini. & 8 & 8 & -5 & -5 & -6 & -3 & -3 & -1 & -1 & -1 \\
\hline
\end{tabular}




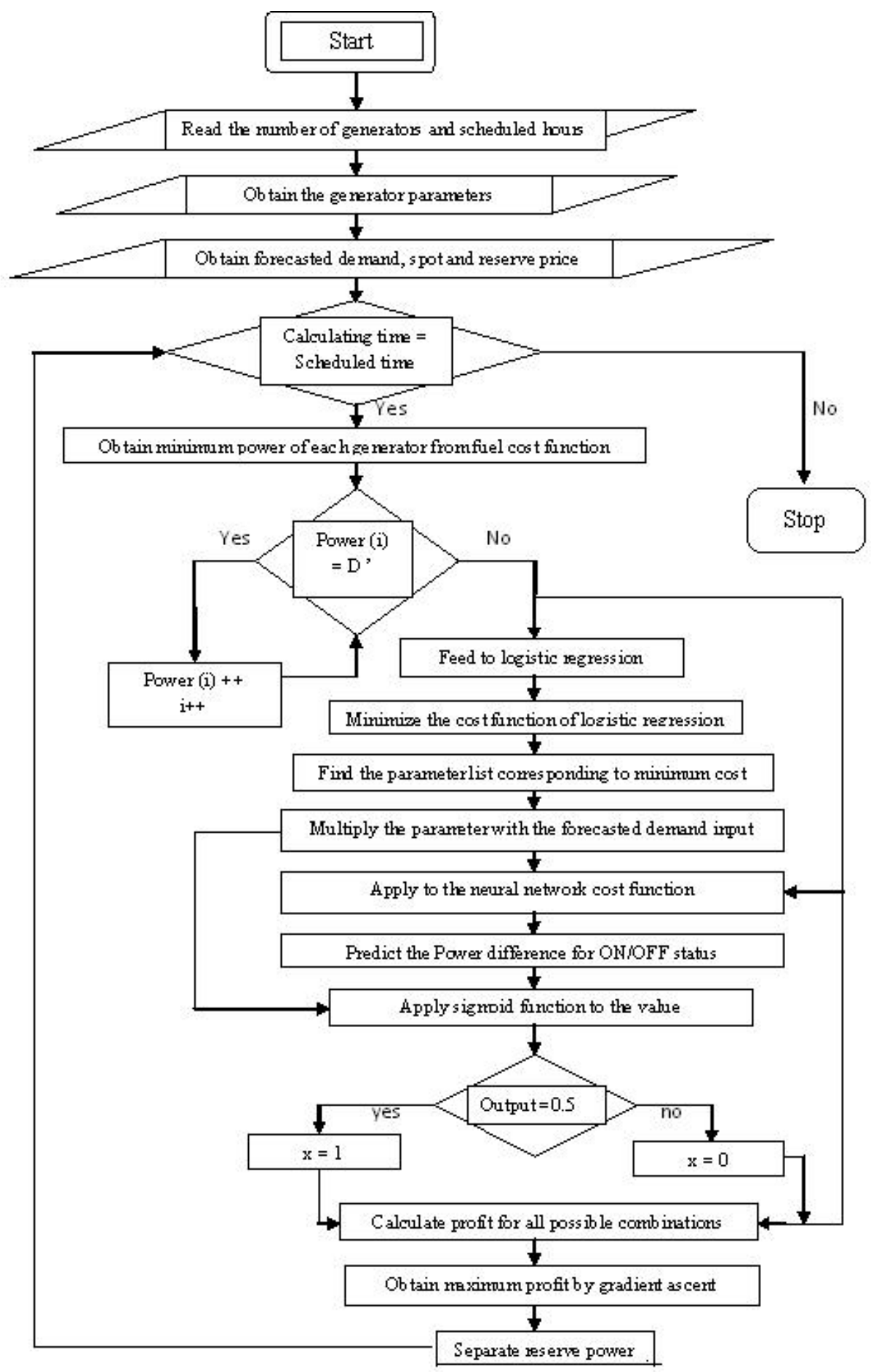

Fig 1.Flow Chart of proposed method 
Table IX

Example of power and Reserve generation of reserve payment method A (10 Units system) $(\mathrm{r}=0.05$, reserve price $=5 \mathrm{X}$ spot price $)$

\begin{tabular}{|c|c|c|c|c|c|c|c|c|c|c|c|c|c|c|c|c|c|c|c|c|c|}
\hline \multirow[t]{3}{*}{$\mathbf{H r}$} & \multicolumn{21}{|c|}{ PBUC ( method A)by proposed method } \\
\hline & \multicolumn{10}{|c|}{ Power(MW) } & \multicolumn{10}{|c|}{ Reserve(MW) } & \multirow[t]{2}{*}{ Profit \$ } \\
\hline & U1 & U2 & U3 & U4 & U5 & U6 & U7 & U8 & U9 & U10 & U1 & $\mathbf{U} 2$ & U3 & U4 & U5 & U6 & U7 & U8 & U9 & U10 & \\
\hline 1 & 345 & 354 & $\mathbf{0}$ & O & $\mathbf{0}$ & O & $\mathbf{0}$ & $\mathbf{0}$ & $\mathbf{0}$ & $\mathbf{0}$ & $\mathbf{0}$ & 70 & $\mathbf{0}$ & $\mathbf{0}$ & 0 & O & 0 & 0 & 0 & $\mathbf{0}$ & 3907.3 \\
\hline 2 & 370 & 379 & $\mathbf{0}$ & $\mathbf{0}$ & $\mathbf{0}$ & 0 & $\mathbf{0}$ & O & O & $\mathbf{0}$ & 75 & $\mathbf{0}$ & $\mathbf{0}$ & 0 & 0 & O & 0 & O & 0 & O & 4076.3 \\
\hline 3 & 420 & 429 & $\mathbf{0}$ & $\mathbf{0}$ & $\mathbf{0}$ & $\mathbf{0}$ & $\mathbf{0}$ & $\mathbf{0}$ & $\mathbf{0}$ & $\mathbf{0}$ & $\mathbf{0}$ & $\mathbf{0}$ & $\mathbf{0}$ & $\mathbf{0}$ & $\mathbf{0}$ & $\mathbf{0}$ & $\mathbf{0}$ & 0 & 0 & 0 & 5153.7 \\
\hline 4 & 455 & 456 & 0 & O & O & $\mathbf{0}$ & 0 & $\mathbf{0}$ & $\mathbf{0}$ & 0 & 0 & 0 & $\mathbf{0}$ & 0 & 0 & O & 0 & $\mathbf{0}$ & $\mathbf{0}$ & O & 5127.3 \\
\hline 5 & 455 & 456 & 0 & 0 & 0 & 0 & 0 & 0 & 0 & 0 & 0 & 0 & 0 & 0 & 0 & 0 & 0 & 0 & 0 & 0 & 5673.3 \\
\hline 6 & 455 & 456 & 0 & 0 & 0 & 0 & 0 & 0 & 0 & 0 & 0 & 0 & 0 & 0 & 0 & O & 0 & O & 0 & O & 5400.3 \\
\hline 7 & 455 & 456 & 0 & 0 & 0 & 0 & 0 & $\mathbf{0}$ & $\mathbf{0}$ & $\mathbf{0}$ & 0 & 0 & $\mathbf{0}$ & 0 & $\mathbf{0}$ & 0 & 0 & O & 0 & O & 4990.8 \\
\hline 8 & 455 & 456 & 0 & 0 & 0 & 0 & 0 & 0 & 0 & 0 & 0 & 0 & 0 & 0 & 0 & 0 & 0 & 0 & 0 & 0 & 4672.3 \\
\hline 9 & 455 & 456 & 0 & O & 0 & 0 & 0 & 0 & 0 & 0 & 0 & 0 & 0 & 0 & 0 & 0 & 0 & 0 & 0 & O & 5263.8 \\
\hline 10 & 455 & 456 & 0 & 0 & 0 & O & 0 & 56 & 0 & 0 & 0 & 0 & 0 & 0 & 0 & 0 & 0 & 0 & 0 & 0 & 11401 \\
\hline 11 & 455 & 456 & 0 & 0 & 0 & 0 & 0 & 56 & 56 & 0 & 0 & 0 & O & 0 & 0 & 0 & 0 & 0 & 0 & O & 12326 \\
\hline 12 & 455 & 456 & 0 & 0 & 0 & 0 & 0 & 56 & 56 & 56 & 0 & 0 & 0 & 0 & 0 & O & 0 & O & 0 & 0 & 14068 \\
\hline 13 & 455 & 456 & 0 & 0 & 0 & 0 & O & 56 & 56 & 56 & 0 & 0 & 0 & 0 & 0 & 0 & 0 & 0 & 0 & 0 & 6468 \\
\hline 14 & 455 & 456 & 0 & 0 & 0 & 0 & 0 & 56 & 56 & 56 & 0 & 0 & 0 & 0 & 0 & 0 & 0 & 0 & 0 & 0 & 6360 \\
\hline 15 & 455 & 456 & 0 & 0 & 0 & 0 & 0 & 56 & 56 & 56 & 0 & 0 & 0 & 0 & 0 & O & 0 & 0 & 0 & 0 & 4204 \\
\hline 16 & 436 & 455 & 0 & 0 & 0 & 0 & 0 & 56 & 56 & 56 & 0 & 0 & 0 & 0 & 0 & 0 & 0 & 0 & 0 & 0 & 3823.9 \\
\hline 17 & 411 & 420 & 0 & 0 & 0 & 0 & 0 & 56 & 56 & 56 & 0 & 0 & 0 & 0 & 0 & O & 0 & 0 & 0 & 0 & 3512 \\
\hline 18 & 455 & 456 & 0 & 0 & 0 & 0 & 0 & 56 & 56 & 56 & 0 & 0 & 0 & 0 & 0 & 0 & 0 & 0 & 0 & O & 3719 \\
\hline 19 & 455 & 456 & 0 & 0 & 0 & 0 & 0 & 56 & 56 & 56 & 0 & 0 & 0 & 0 & 0 & 0 & 0 & 0 & 0 & 0 & 3881 \\
\hline 20 & 455 & 456 & 0 & 0 & 0 & 0 & 0 & 56 & 56 & 56 & 0 & 0 & 0 & 0 & 0 & 0 & 0 & O & 0 & 0 & 4366 \\
\hline 21 & 455 & 456 & 0 & 0 & 0 & 0 & 0 & 56 & 56 & 56 & 0 & 0 & 0 & 0 & 0 & 0 & 0 & 0 & 0 & 0 & 4851 \\
\hline 22 & 455 & 456 & 0 & 0 & 0 & 0 & 0 & 56 & 56 & 56 & 0 & 0 & O & 0 & 0 & O & 0 & O & 0 & O & 4689 \\
\hline 23 & 0 & 455 & 0 & 0 & 0 & 0 & 0 & 56 & 56 & 56 & 0 & 0 & 0 & 0 & 0 & 0 & 0 & 0 & 0 & 0 & 1586 \\
\hline 24 & 0 & 455 & 0 & 0 & 0 & 0 & 0 & 56 & 56 & 56 & 0 & 0 & 0 & 0 & 0 & O & 0 & 0 & 0 & 0 & 1462 \\
\hline & & & & & & & & & Tota & fit \$ & & & & & & & & & & & $1,30,990$ \\
\hline
\end{tabular}

Table X

Example of power and Reserve generation of reserve payment method B (10 Units system) $(\mathrm{r}=0.05$, reserve price $=0.01 \mathrm{X}$ spot price $)$

\begin{tabular}{|c|c|c|c|c|c|c|c|c|c|c|c|c|c|c|c|c|c|c|c|c|c|}
\hline $\mathbf{H r}$ & \multicolumn{21}{|c|}{ PBUC(method B) by proposed method } \\
\hline & \multicolumn{10}{|c|}{ Power(MW) } & \multicolumn{10}{|c|}{ Reserve(MW) } & \multirow[t]{2}{*}{ Profit \$ } \\
\hline & U1 & U2 & U3 & U4 & U5 & U6 & U7 & U8 & U9 & U10 & U1 & U2 & U3 & U4 & U5 & U6 & U7 & U8 & U9 & U1 & \\
\hline 1 & 345 & 354 & 0 & $\mathbf{0}$ & 0 & $\mathbf{0}$ & 0 & 0 & 0 & $\mathbf{0}$ & $\mathbf{0}$ & 70 & 0 & 0 & 0 & 0 & 0 & 0 & $\mathbf{0}$ & 0 & 3598 \\
\hline 2 & 370 & 379 & $\mathbf{0}$ & $\mathbf{0}$ & $\mathbf{0}$ & $\mathbf{0}$ & $\mathbf{0}$ & $\mathbf{0}$ & $\mathbf{0}$ & $\mathbf{0}$ & 75 & $\mathbf{0}$ & $\mathbf{0}$ & $\mathbf{0}$ & $\mathbf{0}$ & $\mathbf{0}$ & $\mathbf{0}$ & $\mathbf{0}$ & $\mathbf{0}$ & $\mathbf{0}$ & 3744 \\
\hline 3 & 420 & 429 & $\mathbf{0}$ & $\mathbf{0}$ & $\mathbf{0}$ & 0 & 0 & 0 & 0 & 0 & 0 & 0 & 0 & 0 & 0 & 0 & 0 & 0 & 0 & O & 5153 \\
\hline 4 & 455 & 456 & 0 & 0 & 0 & 0 & 0 & O & 0 & 0 & 0 & 0 & 0 & 0 & 0 & 0 & 0 & 0 & 0 & 0 & 5127 \\
\hline 5 & 455 & 456 & 0 & 0 & 0 & 0 & 0 & O & 0 & 0 & 0 & 0 & 0 & 0 & 0 & 0 & 0 & 0 & 0 & 0 & 5673 \\
\hline 6 & 455 & 456 & 0 & O & O & 0 & 0 & 0 & 0 & 0 & 0 & 0 & 0 & 0 & 0 & 0 & 0 & 0 & $\mathbf{0}$ & 0 & 5400 \\
\hline 7 & 455 & 456 & 0 & 0 & 0 & 0 & 0 & 0 & 0 & 0 & $\mathbf{0}$ & 0 & 0 & 0 & 0 & 0 & 0 & 0 & 0 & 0 & 4990.8 \\
\hline 8 & 455 & 456 & O & 0 & 0 & 0 & 0 & O & 0 & 0 & 0 & 0 & 0 & 0 & 0 & 0 & 0 & 0 & 0 & 0 & 4672.3 \\
\hline 9 & 455 & 456 & O & 0 & 0 & 0 & 0 & O & 0 & 0 & 0 & 0 & 0 & 0 & 0 & 0 & 0 & 0 & 0 & O & 5263.8 \\
\hline 10 & 455 & 456 & 0 & O & 0 & 0 & 0 & 56 & 0 & 0 & 0 & 0 & 0 & 0 & 0 & 0 & 0 & 0 & 0 & 0 & 11401 \\
\hline
\end{tabular}




\begin{tabular}{|c|c|c|c|c|c|c|c|c|c|c|c|c|c|c|c|c|c|c|c|c|c|}
\hline 11 & 455 & 456 & 0 & 0 & 0 & 0 & O & 56 & 56 & 0 & O & O & 0 & 0 & 0 & O & O & 0 & 0 & 0 & 12326 \\
\hline 12 & 455 & 456 & 0 & 0 & 0 & 0 & 0 & 56 & 56 & 56 & 0 & 0 & 0 & 0 & 0 & 0 & 0 & 0 & 0 & 0 & 14068 \\
\hline 13 & 455 & 456 & 0 & 0 & 0 & 0 & 0 & 56 & 56 & 56 & 0 & 0 & 0 & 0 & 0 & 0 & 0 & 0 & 0 & 0 & 6468 \\
\hline 14 & 455 & 456 & 0 & 0 & 0 & o & 0 & 56 & 56 & 56 & 0 & 0 & 0 & o & 0 & o & o & 0 & 0 & 0 & 6360 \\
\hline 15 & 455 & 456 & 0 & 0 & 0 & 0 & 0 & 56 & 56 & 56 & 0 & O & 0 & 0 & 0 & 0 & 0 & O & O & O & 4204 \\
\hline 16 & 436 & 455 & 0 & 0 & 0 & 0 & 0 & 56 & 56 & 56 & 0 & 0 & 0 & 0 & 0 & 0 & 0 & 0 & O & 0 & 3823.9 \\
\hline 17 & 411 & 420 & 0 & 0 & 0 & 0 & 0 & 56 & 56 & 56 & 0 & 0 & 0 & O & 0 & 0 & 0 & O & 0 & 0 & 3512 \\
\hline 18 & 455 & 456 & 0 & 0 & 0 & 0 & 0 & 56 & 56 & 56 & 0 & 0 & 0 & 0 & 0 & 0 & 0 & 0 & O & 0 & 3719 \\
\hline 19 & 455 & 456 & 0 & 0 & 0 & 0 & 0 & 56 & 56 & 56 & 0 & O & 0 & 0 & 0 & 0 & 0 & 0 & O & 0 & 3881 \\
\hline 20 & 455 & 456 & 0 & O & 0 & 0 & 0 & 56 & 56 & 56 & 0 & O & 0 & O & 0 & 0 & 0 & O & O & 0 & 4366 \\
\hline 21 & 455 & 456 & 0 & 0 & 0 & 0 & O & 56 & 56 & 56 & 0 & O & O & O & 0 & O & 0 & O & 0 & O & 4851 \\
\hline 22 & 455 & 456 & 0 & 0 & 0 & 0 & 0 & 56 & 56 & 56 & 0 & O & 0 & 0 & 0 & 0 & 0 & $\overline{0}$ & O & 0 & 4689 \\
\hline 23 & 0 & 455 & 0 & 0 & 0 & 0 & 0 & 56 & 56 & 56 & 0 & O & 0 & O & 0 & 0 & 0 & O & 0 & 0 & 1586 \\
\hline 24 & 0 & 455 & 0 & 0 & 0 & 0 & 0 & 56 & 56 & 56 & 0 & O & 0 & 0 & 0 & O & 0 & 0 & 0 & 0 & 1462 \\
\hline \multicolumn{20}{|c|}{ Total Profit \$ } & \multicolumn{2}{|r|}{$1,30,349$} \\
\hline
\end{tabular}

\section{References}

1. Wood A.J. and Wollenberg B.F. (1996), Power Generation Operation and Control, $2^{\text {nd }}$ ed. New York: Wiley.

2. Maifeld T. and Sheble G. (1996), Genetic-based unit commitment, IEEE Transactions on Power Systems, 11(3), pp. 1359.

3. Allen E.H. and IIic M.D. (2000), Reserve markets for power system reliability, IEEE Trans. Power systems, 15, pp. 228-233.

4. Richter C.W. Jr. and Sheble G.B. (2000), A profitbased unit commitment GA for the competitive environment, IEEE Trans. Power Systems, 15, pp. 715-721.

5. Attaviriyanupap P., Kita H., Tanaka E., and Hasegawa J., A hybrid evolutionary programming for solving thermal unit commitment problem," in Proc. $12^{\text {th }}$ Annual Conference Power and Energy Society Institution of .Electrical .Engineers, Japan.

6. Attaviriyanupap P., Kita H., Tanaka E., and Hasegawa J. (2003), A Hybrid LR-EP for solving new profitBased UC Problem Under competitive Environment, IEEE Transactions on Power Systems, 18, pp. 229237.

7. Narayana Prasad Padhy (2004), Unit Commitment-A Bibliographical Survey, IEEE Trans. Power systems, 19(2).
8. Saadat H. (2002), Power System Analysis, $2^{\text {nd }}$ Ed. Milwaukee: McGraw- Hill, pp. 189 - 313.

9. Christober Asir Rajan C.and Mohan M.R. (2004), An Evolutionary Programming - Based Tabu Search Method For Solving The unit Commitment Problem, IEEE Transactions On Power Systems, 19(1).

10. Li, T., and Shahidehpour, M. (2005), Price- based unit commitment: A case of lagrangian relaxation versus mixed integer programming, IEEE Transaction on Power System, 20(4), pp. 2015- 2025.

11. Chandram K., Subrahmanyam N. (2008), New approach with Muller method for Profit Based Unit Commitment, Proceedings of IEEE Power Systems, pp. 1-8.

12. Yamin H., Al-Agtash S., and Shahidehpour M. (2004), Security-constrained optimal generation scheduling for GENCOs, IEEE Transactions on Power Systems, 19(3), pp. 1365-1372.

13. Yamin H.Y., Tao Li, and Mohammad Shahidehpour (2005), Fuzzy self-scheduling for Gencos, IEEE Transactions on Power Systems, 20(1), pp. 503-505.

14. Zuyi Li, and Mohammad Shahidehpour (2005), Security-Constrained Unit Commitment for Simultaneous Clearing of Energy and Ancillary Services Markets, IEEE Transactions on Power Systems, 20(2), pp. 1079-1088.

15. Yamin H.Y., EI-Dwairi Q, Shahidehpour S.M. (2007), A new approach for Gencos profit based unit commitment in day-ahead competitive electricity 
markets considering reserve uncertainty, IEEE Transactions on Power Systems , 29, pp. 609-616.

16. Maria Dicorato, Giuseppe Forte, Michele Trovato and Ettore Carusod (2009), Risk-Constrained Profit Maximization in Day-Ahead Electricity Market, IEEE Transactions on Power Systems, 24(3), pp. 11071114.

17. Lau T.W., Chung C.Y., Wong K.P., Chung T.S. and Ho S.L. (2009), Quantum-Inspired Evolutionary Algorithm Approach for Unit Commitment, IEEE Transactions on Power Systems, 24(3), pp. 1503 1512.

18. Pablo A. Ruiz, C. Russ Philbrick, and Peter W. Sauer (2010), Modeling Approaches for Computational Cost Reduction in Stochastic Unit Commitment Formulations, IEEE Transactions on Power Systems, 25(1), pp. 588-589.

19. Takeshi Seki, Nobuo Yamashita, and Kaoru Kawamoto (2010), New Local Search Methods for Improving the Lagrangian-Relaxation-Based Unit Commitment Solution, IEEE Transactions on Power Systems, 25(1), pp. 272-283

20. Yun-Won Jeong, Jong-Bae Park, Se-Hwan Jang, and Kwang Y. Lee(2010), A New Quantum-Inspired Binary PSO: Application to Unit Commitment Problems for Power Systems, IEEE Transactions on Power Systems,. 25(3), pp. 1486 -1495

21. Amin Khodaei and Mohammad Shahidehpour (2010), Transmission Switching in Security-Constrained Unit Commitment, IEEE Transactions on Power Systems,. 25(4), pp. 1937-1945.

22. Ting,T.O and Rao, M.V.C. (2006) 'A Novel Approach for Unit Commitment Problem via an Effective Hybrid Particle Swarm Optimization' IEEE Transactions On Power Systems, Vol. 21, No. 1, pp.411-418.

23. Jing Yu, Jianzhong Zhou, Wei Wu, and Junjie Yang, Wei Yu(2004), Solution of The Profit-Based Unit Commitment Problem By Using Multi-Agent System, Proceedings of $5^{\text {th }}$ World Congress on intelligent Control and Automation, pp.5079-5083.

24. Bavafa M, Navidi, N, Monsef, H, A new approach for Profit-Based Unit Commitment using Lagrangian relaxation combined with ant colony search algorithm, Proceedings of IEEE Power Systems.

25. Yuan Xiaohui. ,Yuan Yanbin, Wang Cheng .,and
Zhang Xiaopan, (2005),An Improved PSO Approach for Profit - based Unit Commitment in Electricity Market, in IEEE Proceedings of Transmission and Distribution Conference, pp.1 - 4.

26. Victorie T.A.A., and Jeyakumar A.E.(2005),Unit commitment by a tabu- search-based hybridoptimization Technique, IEE Proceedings of Generation, Transmission, Distribution, pp.563 -574.

\section{Biographies}

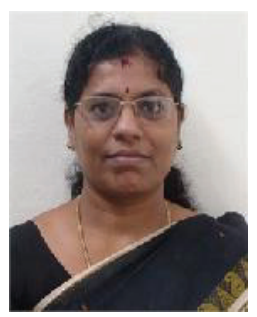

A.Amudha was born in 1969. She received B.E Electrical and Electronics Degree from Bharathiar University, Coimbatore, India in 1990 and M.E Degree in Power System from Madurai Kamaraj University, Madurai, India in 1992. She is currently pursuing Ph.D. degree in Power Systems at Anna University, Trichy, India. Currently, she is an Associate professor in the Department of Electrical and Electronics at Sri Krishna College of Engineering and Technology, Coimbatore, India. Ms. A .Amudha is a member of ISTE, MIE in India and IEEE member.

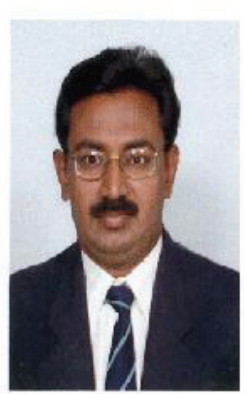

Christober Asir Rajan born on 1970 and received his B.E. (Distn.) degree (Electrical and Electronics) and M.E. (Distn.) degree (Power System) from the Madurai Kamaraj University (1991 \& 1996), Madurai, India. And he received his postgraduate degree in DI.S. (Distn.) from the Annamalai University, Chidambaram (1994) $\mathrm{He}$ received his $\mathrm{Ph} . \mathrm{D}$ in Power System from Anna University (2001-2004), Chennai, India. He published technical papers in International \& National Journals and Conferences. $\mathrm{He}$ is currently working as Associate Professor in the Electrical Engineering Department at Pondicherry Engineering College, Pondicherry, India. His area of interest is power system optimization, operational planning and control. He acquired Member in ISTE and MIE in India and Student Member in Institution of Electrical Engineers, London. 